\title{
Mapping Enabling Technologies for Supply Chains with Future Scenarios
}

\author{
Pedro Pinho Senna, Markus Stute, Sebastien Balech, \\ and Andrea Zangiacomi
}

\begin{abstract}
Driven by the current digital transformation, European companies rely on accurate forecasting of future trends and prediction of most useful technologies in order to maintain their competitive edge. For this purpose, the mapping of enabling technologies to future scenarios becomes a valuable tool for practitioners and researchers alike, especially when considering the disruptive events that surround SCs design, implementation and management. This research sets forth to fill this gap by presenting a technology mapping of enabling technologies based on technology portfolio approach, expert elicitation and literature. The final outcome is the mapping of the enabling technologies to the characteristics of the future European SC scenarios.
\end{abstract}

Keywords Enabling technologies $\cdot$ Supply chain strategies $\cdot$ Technology mapping

P. P. Senna (殴

INESC TEC Institute for Systems and Computer Engineering, Technology and Science, Campus da FEUP, Rua Dr. Roberto Frias, 4200-465 Porto, Portugal

e-mail: pedro.senna@inesctec.pt

M. Stute

Fraunhofer Institute for Material Flow and Logistics, Joseph-von-Fraunhofer-Str. 2-4, 44137

Dortmund, Germany

e-mail: markus.stute@iml.fraunhofer.de

S. Balech

PNO Consultant, Avenue de la Joyeuse Entrée 1, 1040 Brussels, Belgium

e-mail: sebastien.balech@gmail.com

\footnotetext{
A. Zangiacomi

Institute of Intelligent Industrial Technologies and Systems for Advanced Manufacturing, National Council of Research (STIIMA-CNR), Via Alfonso Corti, 12-20133 Milano, Italy e-mail: andrea.zangiacomi@stiima.cnr.it
} 


\section{Introduction}

On recent years, great attention has been given to robotics, Artificial Intelligence (AI), computer science, big data and other digital technologies (Lee et al. 2014; Mosterman and Zander 2016; Khorram et al. 2017). These technologies are changing the discrete manufacturing, process and logistics \& distribution industrial sectors. Some recent attempts have been done to shed light on their application regarding the SC level, such as: (a) link between Industry 4.0 and lean production (Buer et al. 2018); (b) importance of Internet of Things (IoT) on SC management; (c) the impact of 3D printing on SC processes and performances (Liu et al. 2014; Oettmeier and Hofmann 2016; Li et al. 2017); and, (d) the change in short-term SC scheduling in smart factories (Ivanov et al. 2016).

These technologies have the potential to revolutionise operations and SC management (Brennan et al. 2015; Holmström et al. 2016; Rüßmann et al. 2015) by focusing on future customer demands, effective resource management and data generation and exchange. This will enable the creation of a product, or delivering a service, in a faster, cheaper, more efficient and more sustainable fashion. Companies are making increasing efforts to improve their own processes. Nevertheless, currently more than ever, it is important to "open the doors" and have an integrated approach with upstream and downstream supply chains (SC) bearing new strategies as well as appropriate technological support.

Considering the growing relevance of technologies for SC and specially their large and broad expected impact, this chapter aims at: (1) mapping the enabling technologies with the SC of the future scenarios which were identified and discussed in Stute et al. (2020) and, (2) mapping the technologies that are expected to contribute to the SC strategic dimensions. This was achieved using the technology mapping methodology, based on the technology portfolio approach and the use of Table Management Tool, expert elicitation, and through literature review.

SC competitiveness is determined by several key factors such as selection of raw materials, SC partners, choice of markets and service offering strategies and technology. Therefore, these factors have crucial implications on the development and improvement of SC performance (mostly linked to enhancements of agility, transparency, reliability and sustainability). These implications support the choice of different enabling technologies aimed at distinct SC strategies, thus providing the technology mapping presented as the result of this chapter.

The chapter has the following structure. The methodology used is presented in Sect. 2. The technology mapping for each specific future SC scenario is detailed in Sect. 3. The overview of the technology mapping is presented in Sect. 4, and the conclusions are portrayed in Sect. 5. 


\section{Methodology}

Technology management research field, which encompasses technology foresight and technology forecasting research, can be organized with respect to the use of technology in business strategies and operations. This entails the connection between engineering, science and management disciplines focused on development and implementation of technological capabilities for accomplishing strategic and operational objectives (Council 1987). It is, therefore, a merge between operations management and industrial technology, with activities aimed at production and operations management, project management, quality control and general management principles (ATMAE_-The Association of Technology 2009).

Technology mapping methodologies are part of technology foresight research (Chen et al. 2012; Gudanowska 2016), and are the focus of this chapter, which aims to describe the methodological stages for achieving the intended mapping of enabling technologies onto the SC strategies of future scenarios. Therefore, these technology mapping methodologies are discussed in more detail on subsections below, first through a brief introduction of the concept and overview of technology foresight, followed by the detailed stages required on technology mapping methodologies, while also presenting the methodological framework used in this chapter.

The overall scheme highlighting the main steps to achieve the intended results can be observed in Fig. 1.

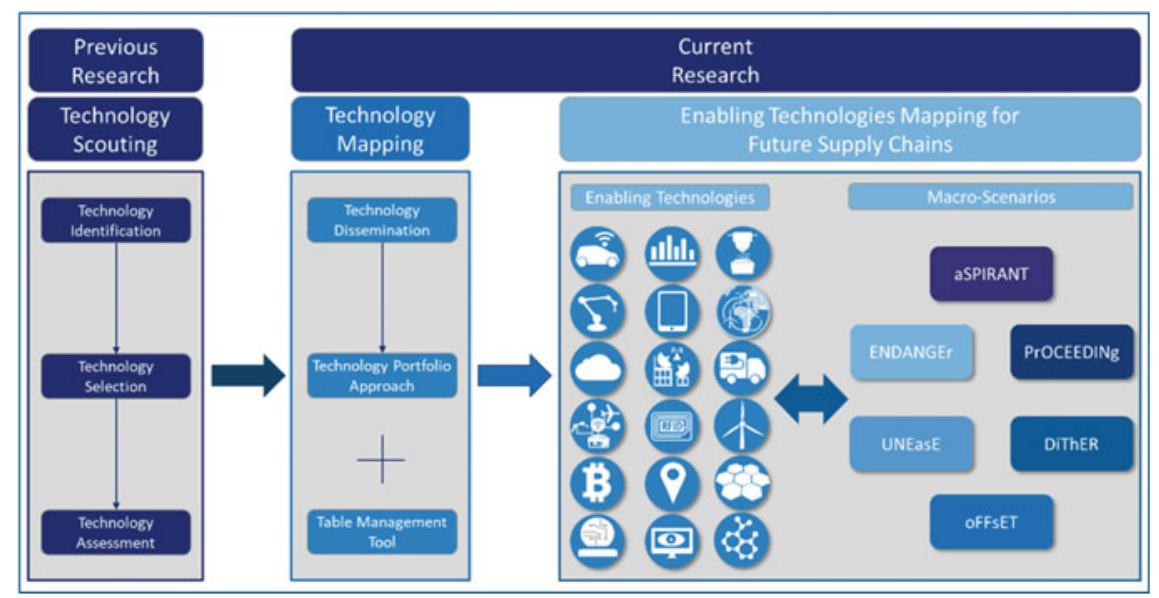

Fig. 1 Methodological framework for this study 


\subsection{Technology Foresight-Concept and Overview}

The main assumption of technology foresight is the presence of interested stakeholders' groups aimed at taking meaningful action and being open minded to innovative ideas (Gudanowska 2016). In other words, foresight is an attempt at linking observations of shift dynamics with current decision-making and indicating possible development schemes for a future state beforehand (Warnke and Heimeriks 2008). Hence, a research can be characterized inside the technological foresight research area whenever the goal is the development of technological solutions or needs, incurring on the development of that research area.

Methods used for technology foresight are vast within a specialized literature (Porter 2010), such as workshops, technology watch, bibliometrics, surveys, growth curve modelling, requirements analysis, quantitatively based scenarios, Data Envelopment Analysis (DEA) and trend impact analysis. Since technology management and technology foresight belong to the field of strategic decision-making, they involve the use of prioritization methods, which may facilitate decision-making based on different alternatives or on different scenarios and strategies, as in this research (Gudanowska 2016). Technology scouting and mapping are methodologies belonging to the technology foresight research field, and are complementary to each other with the common goal to portray technologies for a given activity, process and/or objective (Gudanowska 2014, 2016).

Scientific literature breaks the process of technology mapping into phases, or functions, with a general agreement of requiring at least four of these functions: Technology Identification (TI), Technology Selection (TS), Technology Assessment (TA) and Technology Dissemination (TD; Rohrbeck et al. 2006). TI, TS and TA functions have been presented in Stute et al. (2020), in the scouting of 18 enabling technologies (Arasti and Moghaddam 2010; Rohrbeck et al. 2006).

\subsection{Technology Mapping}

Technology mapping allows for a qualitative analysis of technologies and to examine analogies among them. On this perspective, it is important that these analyses take place with the same rigor as the structured approach to collect information about each technology, and aim towards presenting a justified image of their current and future states (Roper et al. 2011). Therefore, this methodology should favour an analytic work focused at expanding the gathered knowledge while making its interpretation easier, in order to distinguish such method from a simple review and record of the data on technologies (Gudanowska 2016).

In order to establish technological development trends, it is essential to determine the current state of technology development and the elements related to such technology. Bearing this goal in mind, accounting for the evolution of technological foresight research based on future-oriented technology analysis is crucial (Cagnin et al. 
2013). The switch from foresight research to general future analysis to technology focus on future analysis is the basis for diagnostic activities. Technology mapping stands under this new vision of technology foresight among other methods, bearing applications that enhance the process of technology identification and gather most knowledge regarding distinguished technologies, which are used in the technology selection process (Gudanowska 2016).

Technology mapping usually focuses on a sector or an area, being a convenient method for identifying technologies when various firms or industries with different characteristics are considered, as well as multiple products/services for a large number of customers (Khalil 2000). As depicted previously, technology mapping methodology has a four-phase methodological approach for achieving a well-devised Technology Strategy Formulation (Arasti and Moghaddam 2010; Gudanowska 2016; Rohrbeck et al. 2006). This chapter focuses on the fourth and final phase of the methodological route of technology mapping, known as Technology Dissemination (TD); (Rohrbeck et al. 2006). For the purposes of this research, TD's objective is to provide the combination of the identified enabling technologies with the SC strategies and future scenarios in an overview fashion that is useful for companies when adapting to the different contexts and SC strategies.

It is important to stress that the TD phase is a high level stage of the methodological approach for technology mapping. Among others, the methodologies within the technology portfolio approach were considered adequate for this study due to their objective being the cross-referencing of technologies and dimensions for specific conditions (Rohrbeck et al. 2006; Phaal et al. 2006). From these, the approach based on Table Management Tool was selected, with the intention to achieve the final technology mapping and to be consistent with the methodology used for establishing the enabling technologies depicted in Stute et al. (2020) of this book (Phaal et al. 2006).

The table management tool herein used aims to provide information on the combination between technologies and the SC future scenarios or strategies (Phaal et al. 2006). For this purpose, the axes were divided into a number of distinct and specific categories, which, when combined with expert elicitation techniques, permit precise mapping of enabling technologies considering the future scenarios' characteristics and the strategies envisioned for the particular contexts. In our case, we have first mapped the technologies according to the scenario's strategic dimensions, which are: products and services; sourcing and distribution; supply chain configuration; manufacturing systems; sales channels; and sustainability. The scenario's technology mapping derived in this step represents the technological evaluation of each future scenario based on its characteristics, and the related level of adoption of the enabling technologies applied and it has been defined as the scenario technology profile. After this, the different scenario technology profiles were used for a cross-scenario comparison, depicted in Sect. 4, which enabled to classify the profiles, according to their technological level into four different categories: (a) digital masters-wide adoption of most, if not all, enabling technologies; (b) tech fashionistas — reasonable adoption of multiple enabling technologies; (c) tech beginners-low adoption of 


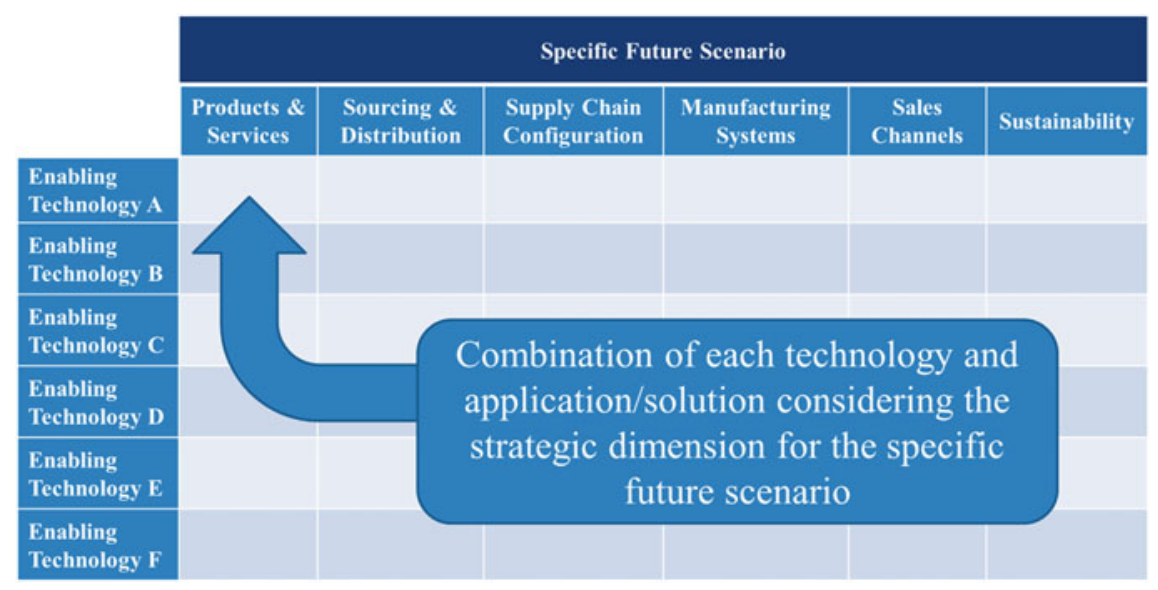

Fig. 2 Structure of technology mapping table for specific future scenario

enabling technologies; (d) tech conservatives — very low, if any, adoption of enabling technologies.

Overall, six tables, one for each future scenario, were prepared following the structure depicted in Fig. 2. The inputs used for the expert elicitation and combinatorial work were: (i) the 18 identified enabling technologies, as presented in Stute et al. (2020); and (ii) the characteristics of the future SC scenarios depicted in Sardesai et al. (2020)—considering the strategic dimensions and SC strategies (identified in Barros et al. 2020).

The results of the technology mapping done for each future scenario are shown in the following section.

\section{Technology Mapping for the Supply Chains of Future Scenarios}

The methodology abovementioned was applied to each of the future scenarios and is depicted separately on the following subsections. The paragraphs describe the mapping of technologies on the basis of each scenario's characteristics and are depicted according to the scenario's strategic dimensions previously mentioned. 


\subsection{Technologies for the Supply Chains of Scenario "aSPIRANT"}

In the "aSPIRANT" scenario, cyber-physical SC networks, heterogeneous nature of sourcing operations, and new market-shaping business models will require development and application of intelligent, complex, interdependent, and end-to-end technology solutions for the SC.

The "aSPIRANT" scenario displays a SC with low uncertainty in demand, while the supply is associated with the predictability of market fluctuations regarding products and services provided. In this sense, advanced technologies that optimize the responsiveness, reliability, and transparency/traceability performance-attributes of SC organizations are considered of crucial importance at the production level. Examples of these advanced technologies include: Artificial Intelligence (e.g. machine learning, deep learning), Data Science (e.g. Big Data Analytics), Autonomous Transport Systems (e.g. drones), and converged usage of heterogeneous technologies, combining industrial IoT connectivity systems, artificial intelligence, and collaborative/autonomous robotics. In the scenario context, digital lean manufacturing systems, allowing for high volume and low complexity production processes, need to be supported and maintained along with enabling technologies.

Moreover, efficient integration of digital technologies (automated control systems, industrial connectivity solutions, and information-tracking systems) with energy and waste management infrastructures of manufacturing facilities will be highly important in the effort to improve on-demand energy supply for production facilities and to minimize waste volume in an eco-friendly manner. In this context, the complementarity of digital technologies depicted on this SC scenario enhance operational scalability and servitisation ecosystem of manufacturing facilities.

As for the business process management in sourcing and distribution, integration of intelligent encrypted contract solutions, cloud-based Business Process as a Service (BPaaS), Platform as a Service (PaaS) and Software as a Service (SaaS), and predictive data analytics into procurement organizations will increase SC agility and decrease operational/transactional costs. Furthermore, to build omnichannel excellence, procurement organizations are required to find smart implementation techniques of servitisation technologies, while leveraging Artificial Intelligence with industrial IoT and high-performance computing solutions. In addition, location technologies will be useful for tracking and traceability of goods and shipments, being capable of suggesting optimal location to consumers where it is possible to collect their orders and inform about multiple delivery systems (Deloitte 2015). Moreover, Visual Computing (e.g. Augmented Reality) is going to provide customers with a seamless omnichannel experience by closing the channel gap at various online and offline touch points. For example, it allows to animate products or their packaging, de-saturating products in the physical assortment, to personalize their choice set, offering better price comparisons (Hilken et al. 2018). 
In the context of closed-loop SC systems and lean manufacturing environments, there are various types of waste streams that will emerge within production: transport, inventory, motion, waiting time, over-processing, over-production, and defects. Integration of identification technologies and location technologies within the manufacturing facilities may increase efficiency in tracking waste streams in the production plants, while also providing service verification and productivity data on manufacturing waste inventory. On the other hand, cloud computing systems, also for Enterprise Resource Planning (ERP) solutions, might help to structure and tailor resource management behaviour of a procurement organization into a closed-loop business process flow. As for the impact of green technologies in manufacturing and process industry, it is difficult to depict, explicitly, technology use development paths in integrating these solutions within the existing manufacturing and processing infrastructure, as there is no one-size-fits-all business model enabling energy efficiency in industrial settings.

In this scenario, cloud-based computing systems will be used at different scales. The cloud-based computing, particularly manufacturing execution systems and ERPenabled operations' management technologies, leveraged by the use of AI and advanced algorithmics, may increase investment in advanced solutions for energy management on the factory floor. At the logistics level, cloud-based SaaS solutions enable further the automation of inventory solutions, open direct sales channels, and develop further personalized shipping solutions.

Additive manufacturing and innovative energy infrastructure will lead to achieve this transition towards a closed-loop and green SC. The emergence of smart materials, as well as of renewable and new energy sources, will be great assets to accomplish this objective. Smart materials, for instance, can be applied in smart green roofs for insulation, thus improving thermal performance and reducing the energy consumption (Mohamed 2017). Similarly, they may be used as devices for temperature changes sensing, which can be shown through colour response capabilities, thus being especially important in emergency situations inside factories, industries and public buildings (Makakli 2017). Furthermore, alternative propulsion systems will greatly participate to this transition. The use of IoT aids companies towards achieving better understanding of the current suppliers' performance, while frequently tracking and benchmarking performance over time. This is also true when considering sustainability aspects, such as real-time carbon footprint monitoring, combined with vendor/suppliers' historical performance and sustainability data collection, through the use of Blockchain technologies, for providing improvements on sustainability performance (Kouhizadeh and Sarkis 2018). Moreover, the use of Visual Computing technologies such as VR and AR can contribute to increase operators' capabilities by creating a virtual environment that simulates the plant design or specifics tasks (Mattson et al. 2018).

The future emergence of smart contracts and Blockchain will enable to face the challenge related to the legal dimension. This would be associated with the communication infrastructure. Development of sensors and their accuracy will lead to predominance of smart maintenance and aid on the development of the green SC. In addition, the use of $5 \mathrm{G}$ as network backbone for IoT and digital technologies greatly improves 
traffic management in urban areas, thus reducing traffic congestion, driving time and vehicular pollutants (West 2016).

\subsection{Technologies for the Supply Chains of Scenario "PrOCEEDINg"}

The "PrOCEEDINg" scenario presents a customization-driven market, diverse sourcing and distribution operations, and the increasing focus on individualism aided by the DIY society, all of which will require SC strategies with fast response-time, posing leagile characteristics, while also being complex and interdependent in nature.

Since the SC for the "PrOCEEDINg" scenario presents predictable demand and supply combined with customized products and servitisation and the presence of high levels of digitalisation, it is paramount that the technologies herein focus on responsiveness, reliability, transparency and traceability, as well as flexibility performance-attributes regarding SC companies and industry sectors. Hence, the most important technologies would be Cloud Based Computer Systems (Platform as a Service-PaaS, Software as a Service-SaaS, Business Process as a Service$\mathrm{BPaaS}$ and Infrastructure as a Service-IaaS are all applied for providing backbone into customization aided with servitisation) and Internet of Things (IoT; especially focusing on Cyber-Physical Systems-CPS). IoT is a key technology also for facing the rise of cybersecurity issues given the ever increasing need to rely on digitisation.

The customisation strategies are driven by the combination of high variety with small and medium production facilities, and by wide digital technologies' adoption. Thus, Hyperconnected Factories and Digital Mass Customization strategies are critical, greatly aided by the use of Autonomous Transport Systems (especially Autonomous Transports for last mile delivery) and Additive Manufacturing (with focus on 3D and 4D printing aimed at material extrusion capabilities, powder bed fusion, directed energy deposition and material jetting). These technologies are further supported by the implementation of IoT (through Process intelligence, machine to machine real-time communication and sensor technologies for devices in warehouses), as well as Communication Infrastructure (as provider of the backbone for the digitalisation process through enabling network communication technologies such as, 5G and NarrowBand-IoT). Furthermore, Energy Infrastructure (mostly focused on Smart Grids and Battery Energy Solutions Systems and Smart and Neural Grids) provides backbone to enable and enhance the afore mentioned technologies.

For a leagile SC, within this scenario, the use of autonomous transport systems and, more specifically, autonomous drones for maintenance and surveillance services are very important. Combined with autonomous robots, they will increase the reliability, responsiveness and in-line production of the SC, conferring it a lean characteristic. Moreover, the composition of an agile SC is enabled by: (i) the reduced use of resources such as energy; (ii) optimized available working space aided by 
Data Science (especially predictive analytics); and (iii) AI focused on the customisation issues (supported by deep learning algorithms for product demand and SC forecasting).

Additionally, autonomous transports have a significant impact on global distribution through the use of Autonomous ships/vessels and trains, greatly improving reliability and flexibility of the SC distribution. On the other hand, Cloud based computer systems will support companies in handling global outsourcing, which may be achieved through the BPaaS. Cloud based computer systems also supports the omnichannel distribution (by means of SaaS in the form of process intelligence tools aimed at omnichannel monitoring of customer experience), due to the need for multiple channels with different characteristics.

The combination of Consumer to Consumer (C2C) with omnichannel approach requires the implementation of Cloud Based Computer Systems (BPaaS aimed at providing enterprise resource management solutions, and PaaS with focus on smart contract platform for cybersecurity reasons). The logistical issue is tackled using Autonomous Transport Systems with autonomous vehicles and drones for last mile delivery, and autonomous trucks for road freight transport, which greatly increase efficiency of the combined strategies. Moreover, Identification Technologies may provide valuable data about consumers and their interactions with products and services, as well as real-time inventory management. Therefore, they can lead to increase speed of refunds and replacements, which in turn enhances omnichannel responsiveness and reliability, greatly improving SC performance (Group 2018).

Lastly, given the growing concern surrounding circular economy capabilities, green SC and social-responsible strategies, Identification Technologies (i.e. for asset recovery and disposition aiding at minimizing costs and waste) and Location Technologies for object real-time detection and traffic information collection enable the decrease of environmental hazards on internal and external logistics (Kouhizadeh and Sarkis 2018). Additionally, the use of IoT, Cloud Based Computer Systems and Communication Infrastructure (all three technologies providing the backbone through enabling network communication technologies) will play a very important role in securing safe communication and data exchange on activities related to waste management and promoting circular economy in manufacturing environments. Moreover, Alternative Propulsion Systems (both through Advanced Biofuels and Electro Mobility) and Renewable Energy Technologies (Hydrogen Production and Storage, Advanced Biofuels and Automated solar panels cleaning systems) are all technologies that contribute, with increasing levels of importance, to the mitigation of waste generation, reduction of greenhouse gas effects and promotion of resource-efficiency strategies (Kouhizadeh and Sarkis 2018; Tsao et al. 2017).

Through data collection, that can be used to avoid excessive inventory, poor use of capacity, inactive and inefficient transportation and missed production schedules, IoT greatly improves SC closed-loop sustainability aspects (Parry et al. 2016). In addition, 5G network can provide faster data and improve traffic management in urban areas with more efficient route optimisation, especially when compared to current wireless technologies (West 2016). Also, Nanotechnology can be applied 
for energy savings and carbon emissions' reduction in the final product, further increasing SC sustainability performance (OECD 2013).

\subsection{Technologies for the Supply Chains of Scenario "oFFsET"}

The "oFFsET" scenario is characterized by the presence of open borders with reduced sales tariffs, enabling the implementation of an agile manufacturing system based on glocal sourcing and distribution. There is stagnation on digital transformation due to the lack of regulations, which inhibits sustainable development. Thus, the conventional and disruptive production technologies coexist, with global players playing major role, especially concerning financial innovations and constrained digital transformation aided by cyber-physical systems.

This scenario is characterized by the adoption of conservative technologies, such as identification technologies and location technologies used in warehousing activities, customer service functions and tracking for route optimization in freight supply and freight distribution. These types of technologies enable high agility levels particularly important for scenarios with uncertainty in demand and supply. In addition, modular production systems and agile manufacturing systems take advantage of identification technologies mainly for warehousing activities.

Glocal sourcing and distribution include the use of location technologies for the routing optimization. Moreover, products are delivered by means of traditional distribution channels.

Cloud based computer systems, only available for large and global players, will support the sourcing process given that companies have to handle glocal sourcing and distribution, which may be achieved through the Software as a Service (SaaS). Data science, by using the sub-technology predictive analytics, will be used for forecasting demand for mainstream products. High uncertainty in demand and supply requires a more agile $\mathrm{SC}$ with improved design, which greatly profits from the use of identification technologies, predictive analytics and advanced AI algorithms.

The use of 4G/LTE for consumer-behaviour adoption towards more efficient use of resources, as well as for providing faster data connectivity, thus enabling managerial decisions regarding resource-efficiency, are considered the communications' backbone for a resource-efficient SC implementation (West 2016).

\subsection{Technologies for the Supply Chains of Scenario "DiThER"}

The scenario "DiThER" is defined by an increasing influence of digital transformation, dynamic development of autonomous solutions, establishment of electrification 
technologies and green systems, the continuous exploitation of disruptive technologies and investment in smart cities. Still, the digital development is obstructed by stringent legal regulations, data management and privacy issues. The considered scenario is characterized by a high technological level in general (advanced digital features such as data science \& IoT), but there is a lack of an overarching vision, coordination and cooperation in the SC.

For a leagile SC, which is relevant within this scenario, the use of digital technologies, such as data science and AI will be crucial for the agile adaptation of decisions and cost-efficient processes within the SC. Thus, the demand and SC forecasting and the resulting inventory optimisation with the support of predictive and prescriptive analytics and AI (e.g. machine and deep learning) will be a crucial factor to adapt to the uncertain and individual demand.

In order to develop a closed-loop SC, the use of alternative propulsion systems and renewable energy technologies will be very important. As smart cities become the norm in the scenario, the use of energy-efficient autonomous transport systems with alternative propulsion (e.g. advanced biofuels, electro mobility) will increase significantly. In this context, renewable energy technologies (e.g. advanced biofuels) will also be widespread.

Moreover, to implement the closed-loop SC, the use of IoT in the form of sensors and Machine-to-Machine (M2M) communication will represent an essential factor for capturing data on transportation logistics environment and enabling to connect in real-time production lines with SC processes.

The additive manufacturing (3D and 4D printing) will permit the increased individualization and development of a DIY society. Regarding the servitization, Cloud Based Computer Systems, such as Platform (PaaS), Software (SaaS) and Business Process as a Service (BPaaS), will play an important role enabling a digital platform economy.

For what concerns urban manufacturing systems, the use of collaborative and autonomous robots (e.g. smart transport robots), innovative energy infrastructure (e.g. smart and neural grids) and autonomous transport systems, such as autonomous vehicles (e.g. self-driving delivery robots) or drones for the last mile delivery will progress considerably.

The application of data science and AI will be a crucial factor in general for this scenario to enable the full potential of the urban living (e.g. smart routing).

\subsection{Technologies for the SCs of Scenario "UNEasE"}

An unstable political environment is the backbone of the "UNEasE" scenario, displaying a presence of protectionism, economic uncertainty and fragmentation of confederations. The lack of well-established regulations in various fields affects environmental and technological development, therefore, IP protection and customer data are at risk with low investments in cyber-security. Bearing obstacles regarding digital transformation, the agents rely solely on the traditional business to business 
environment, where traditional economy persists aided by the traditional production technologies. Disruptive technologies are implemented solely by big players, which set aside SMEs and Start-ups to compete exclusively on local markets, focusing mostly on customized products aimed at supporting the rise of DIY trends. Moreover, solutions are needed to face the dangerous effects of the climate changes and resource scarcity.

There are some features of the SC strategic dimensions in the "UNEasE" scenario that mainly influence the adoption of the technologies identified previously, like the low digitalization level in the society (including industry). In fact, in this scenario, the traditional economy persists due to the lagging of a clear legislation for data management which worsen a limited level of digitalization with a coexistence of traditional and new technologies. Moreover, there is a problem of unskilled workforce. This means that companies need to be supported in the implementation of new technologies with actions from public bodies that can create awareness through different training programs as well as directly support with actions to finance the introduction of new technologies. In particular, the following technologies can be useful to overcome challenges in this scenario.

Along a SC for customized products, as the one required in this scenario the use of some digital technologies, mainly in the down-stream side, is useful to improve the performance of the network. Companies should adopt technologies like Big Data Analytics and Business Intelligence to support the process of detecting customers' needs and changes in market demand. These technologies can enable to process in an efficient way the vast amount of data from markets and consumers and convert them into meaningful information. The aim is to create customers' profiles and identify new market trends to understand and possibly predict the high variability of the demand. This can have an indirect but positive impact on the management of the SC since these data can be processed in an efficient way to integrate the supplier role. Another technology consists in sensors to collect data for the realization of customized products and identify all the specific peculiar variants and characteristics required by different markets. Sensors are composed of integrated hardware (smart devices) and software (apps) and are configured with unique resource identifiers in Internet (Ding and Jiang 2016). Customers can interact with companies to express their feelings and opinions or co-create personalized products in social media: the interactions enable to capture their real needs. In the Business to Consumer (B2C) relationships these problems are overlapped thanks to the growing number of startups. Start-ups or Fintech companies in fact apply and develop technologies based on social sensors for improving relationships with customers as well as smart contract and mobile apps which support the rise of the sharing economy and improve the relationship between final customers and companies.

Among the production technologies ensuring flexibility and increasing the SC performances in terms of agility, responsiveness and reliability, additive and hybrid manufacturing represent the ones that can be more widely adopted in this scenario. $3 \mathrm{D}$ printing for example is a technology that can make the SC customer- driven, agile and also resource efficient because the amount of residual material or waste remaining after the process is significantly less than in subtractive manufacturing. Moreover, 
additive manufacturing is also a technology that fit well with the emerging urban manufacturing trend. In this scenario, the production phase must be indeed flexible and near located to the market, and the rise of small factories and FabLabs would support the DIY trend. In this sense, 3D-printing enables production of personalized products and components to be brought near to the customer in urban plants, or in specific service centres, available for customers willing to realize their own goods according to peculiar features. In this new urban setting, electric vehicles will be used equipped with location technologies, such as GPS tracking systems, which require well-developed communication infrastructure achievable with the implementation of 5G. The communication and location technologies are useful not only for the local distribution but also to manage global suppliers since the problems related to protectionism and resource scarcity, sometimes, force companies to search materials also in faraway countries: the mentioned technologies enable to gain efficiency in the transport of goods and in the communication along the chain.

Even though the development of green systems is ongoing, given the related high costs and unclear regulations in this scenario, it is foreseen an improvement of the renewable energy technologies and smart grids solutions to make the SC greener. To achieve the goal of a resource efficient SC other technologies can be used as the abovementioned additive manufacturing and the cloud-based systems (Mai et al. 2016). For example, platforms as a service allow companies to optimize resource sharing and procurements among the different plants in the urban area, supporting also online production, distribution and service scheduling and even the customer in the application of the DIY paradigm. In addition, IoT greatly aids resource efficiency, since it allows for data collection which is useful to avoid excessive inventory and missed production schedules (Parry et al. 2016).

After a disruptive event, like natural disasters, the humanitarian SC has to be immediately activated and technologies like IoT (associated with big data analytics), communication infrastructure, smart wearable devices, and location technologies are useful to save lives during the response phase, facing the first emergency step and quickly tracking people. Moreover, during the reconstruction phase, these technologies can be used to manage in an efficient way the distribution of resources: saving as many costs as possible means being able to help more people.

\subsection{Technologies for the Supply Chains of Scenario "ENDANGEr"}

Regarded as the most unstable scenario brought forth within scenario-building projections included, "ENDANGEr" shows a collapse of governments in Europe supported by full protectionism and the fragmentation of confederations. Thus, a global trade shift is observed, with power being transferred to emerging market economies. The presence of frugal mass products, risk-hedging production systems, glocal sourcing with local distribution and simple production systems are justified 
by harsh environmental impacts, boasting resource scarcity and lack of regulations. Hence, resource-efficient SC combined with humanitarian ones are common-place and widely implemented, given the high risk and challenging conditions, especially for companies that must deal with traditional economies being conducted without the presence of intermediaries, enhancing the uncertainty regarding financial resources availability.

This scenario is characterized as the least digitalized, hence it is supported by more traditional SC strategies. Among these, frugal mass products are definitely on the core, partially aided by autonomous and collaborative robots and IoT (mostly through Process Intelligence to support decision making). Given the low demand and high supply risk uncertainty of this scenario, which compels the use of risk-hedging SC strategy, IoT plays a central role through Sensor Technologies.

Sourcing is provided by means of Autonomous Transport Systems, especially Autonomous Vehicles and Drones, despite being implemented on a smaller scale, aimed at supporting the glocal sourcing. On the other hand, distribution is mostly accomplished by Autonomous vehicles for last mile delivery and drones due to the local focus, complemented by Electro Mobility from Alternative Propulsion Systems.

Regarding the low level of digitalisation encountered by companies, production systems will most likely be of simple nature and focused in emerging countries, especially when considering the political shift of power. Likewise, efficient and reconfigurable manufacturing systems are prominent due to the uncertainty surrounding supply, the presence of low variety and large production facilities, as well as timid adoption of autonomous technologies. Therefore, the machine to machine real-time communication and connectivity from Internet of Things, Cyber-Physical Systems implementation and the use of Process Intelligence for decision-making capabilities are considered crucial for the frugal mass products manufacturing capabilities. Moreover, it is expected that Artificial Intelligence will be somewhat prominent, mostly represented through machine learning and deep learning, complimented by Big Data Analytics from Data Science point-of-view.

Sales channels will certainly remain traditional given the economic aspects of the scenario for this SC, hence the need for IoT technologies to rise due to decisionmaking requirements.

From the sustainability aspect, IoT is present, mostly aimed towards resourceefficient and humanitarian SC through sensor technologies adoption, machine to machine real-time communication and connectivity for information exchange. IoT allows for real-time access to information regarding the position and availability of resources, which is considered crucial in decision-making processes related to natural disasters' occurrences (Prasad et al. 2018). 


\section{Discussion and Cross-Scenario Comparison}

This section focuses on providing a cross-scenario comparison regarding the mapping of enabling technologies. It should be noted that this mapping does not have a quantitative value but aims to provide a qualitative vision of the set of technologies which have been considered for each scenario, according to the technological profile of the scenario itself (digital master, tech fashionista, tech beginner, tech conservative) and its other features (e.g. customisation, sustainability, etc.).

We can expect that SC for "aSPIRANT" and "DiThER" macro-scenarios present all enabling technologies implemented. Nevertheless, it should be noted that "aSPIRANT" scenario presents full implementation of the enabling technologies, due to the presence of a highly digitalized environment, categorized as the Digital Masters one, and availability of investments to support the large-scale implementation.

On the other hand, SC of "DiThER" scenario present the trend for being TechFashionistas, in the sense that the implementation of the enabling technologies is sporadic and less withstanding. Furthermore, the "PrOCEEDINg" scenario can also be considered as Digital Masters, with highly digitalized environment and investments, despite lacking the implementation of Blockchain/Distributed Ledger technology due to the presence of an economic environment with Bank and Fintechs collaboration, which may hinder the development of innovative financial distributed exchange solutions between actors.

Otherwise, SC for scenarios "UNEasE", "ENDANGEr" and "oFFsET", being considered Low-Tech (Tech Conservatives or Tech Beginners, depending on the technologies' implementation level and maturity level), have limited application of enabling technologies due to the digital, economic and sustainability characteristics. For this reason, these scenarios are the ones which will require more efforts in order to fill the gaps in terms of technology development and adoption. In the case of the "ENDANGEr" scenario, the presence of Autonomous Transport Systems, Robotics and AI enables the dynamic development of autonomous technologies. Having a world where the traditional role of banks as economic framework requires the implementation of Blockchain enabling technologies, especially cryptocurrencies such as Bitcoin and Ethereum. Regarding "UNEasE" scenario, Smart Materials are used on the production of Mobile and Wearable Devices applied for customized products (enhancing the responsiveness and reliability aspects), as well as on natural disasters occurrences, tackled by Humanitarian/disaster relief SC.

Lastly, the scenario "oFFsET" presents digital impediment and an innate reluctance to accept autonomous technologies, which hinders the implementation of most enabling technologies. Moreover, the unstable Confederations combined with lacking legislation on all major dimensions more than likely will deter major investments required for research, development and implementation of these enabling technologies. Thus, only enabling technologies which are already broadly implemented are present in the SC for "oFFsET" scenario. 


\section{Conclusions}

This chapter presented the enabling technologies for the SC to be implemented in the future scenarios foreseen for the next decade. The proposed methodology was based on technology mapping and technology portfolio approach, with emphasis on the adoption of Table Management Tool. The enabling technologies were evaluated having the SC scenarios and strategies as the basis for their definition, as well as the technology scouting.

The first results were drawn with regards to the SC scenarios and were detailed on Sect. 3. An overview of the findings was presented in the following Sect. 4. Further, given some overlapping on the possible technological applications in different scenarios, a cross-dimension mapping was carried out, where technologies were grouped for each specific SC strategies concerning 6 dimensions: Products \& Services, Sourcing \& distribution, SC Configuration, Manufacturing Systems, Sales Channels and Sustainability. This cross-dimension mapping aims at providing valuable inputs for companies and decision-makers that are looking to implement single strategies or bundles with mixed strategies, thus being able to better decide which enabling technologies to focus on to improve their SC performance.

The results of the technology mapping conducted through this chapter, aimed at linking enabling technologies with scenarios and SC strategies, and constitutes valuable input for roadmapping and policy definition. Most technologies can have a declination for each strategy according to the specific aim. Moreover, a technology can be applied to different strategic dimensions and there is the need for an integrated approach to consider technologies not as standalone solutions but in an integrated way.

One relevant aspect turning out from this mapping is indeed the importance of integrating different technologies which is necessary to fully implement innovative strategies for future SC. The mapping in Sect. 4 does not aim to be exhaustive but to give good examples for the wide range of possible applications.

Acknowledgements We are grateful to all contributors of the Next-Net project team and particularly to Ana Cristina Barros, Ricardo Zimmermann, Rosanna Fornasiero, Irene Marchiori, Cemre Mutlu, Victoria Muerza and Mustafa Çagri Gürbüz. This work was financially supported by the European Union's Horizon 2020 Research and Innovation Program under the Grant Agreement No. 768884 for the project NEXT-NET: Next generation Technologies for networked Europe.

\section{References}

Arasti MR, Moghaddam NB (2010) Use of technology mapping in identification of fuel cell subtechnologies. Int J Hydrogen Energy 35(17):9516-9525

ATMAE - The Association of Technology, MA (2009) (JRW Wright Jr, Producer, \& ATMAE Executive Board) Retrieved 24 June 2018, from ATMAE Venn Diagram: http://www.atmae.org/ page/AboutATMAE? \&hhsearchterms $=\% 22$ technology + and + management + and + definition $\% 22$ 
Barros AC, Senna P, Marchiori I, Kalaitzi D, Balech S (2020) Scenario-driven supply chain charaterization using a multi-dimensional approach. In: Fornasiero et al (ed) Next generation supply chains: a roadmap for research and innovation, Springer

Buer SV, Strandhagen JO, Chan FT (2018) The link between Industry 4.0 and lean manufacturing: mapping current research and establishing a research agenda. Int J Prod Res 56(8):2924-2940

Brennan L, Ferdows K, Godsell J, Golini R, Keegan R, Kinkel S, Srai SJ, Taylor M (2015) Manufacturing in the world: where next? Int J Oper Prod Manage 35(9):1253-1274

Cagnin C, Keenan M, Johnston R, Scapolo F, Barre R (2013) Future-oriented technology analysis: Strategic intelligence for an innovative economy. Springer, Heidelberg

Chen H, Wakeland W, Wu J (2012) A Two-stage technology foresight model with system dynamics simulation and its application in the Chinese ICT industry. Technol Forecast Soc Chang 79:1254 1267

Council US (1987) Management of technology—the hidden competitive advantage. Washington National Academy Press

de Miranda Santo M, Coelho GM, dos Santos DM, Filho LF (n.d.) Text mining as a valuable tool in foresight exercises: a study on nanotechnology. Technol Forecast Soc Change 73:1013-1027

Deloitte (2015) Omni-channel retail—a deloitte point of view. Deloitte AB

Ding K, Jiang P (2016) Incorporating social sensors and CPS nodes for personalized production under social manufacturing environment. Procedia CIRP 56:366-371

Group AM (2018) Why RFID is crucial for omnichannel retailing. Retrieved Nov 01 2018, from https://www.advancedmobilegroup.com/blog/why-rfid-is-crucial-for-omnichannel-retailing

Gudanowska AE (2014) Technology mapping as a tool for technology analysis in foresight studies. 2014 IEEE International Technology Management Conference, Chicago, IL, pp. 1-4

Gudanowska AE (2016) Technology mapping-proposal of a method of technology analysis in foresight studies. Bus Theory Pract 17(3):243-250

Hilken T, Heller J, Chylinski M, Keeling DI, Mahr D, de Ruyter K (2018) Making omnichannel an augmented reality: the current and future state of the art. J Res Interact Mark

Holmström J, Holweg M, Khajavi SH, Partanen J (2016) The direct digital manufacturing (r) evolution: definition of a research agenda. Oper Manage Res 9(1):1-10

Ivanov D, Dolgui A, Sokolov B, Werner F, Ivanova M (2016) A dynamic model and an algorithm for short-term supply chain scheduling in the smart factory industry 4.0. Int J Prod Res 54(2):386-402

Khalil T (2000) Management and technology: the key to competitiveness and wealth creation. McGraw Hill, New York, NY

Khorram NM, Nonino F (2017) Additive manufacturing management: a review and future research agenda. Int J Prod Res 55(5):1419-1439

Kouhizadeh M, Sarkis J (2018) Blockchain practices, potentials, and perspectives in greening supply chains. Sustainability

Lee J, Kao HA, Yang S (2014) Service innovation and smart analytics for industry 4.0 and big data environment. Procedia CIRP 16:3-8

Li Y, Jia G, Cheng Y, Hu Y (2017) Additive manufacturing technology in spare parts supply chain: a comparative study. Int J Prod Res 55(5):1498-1515

Liu P, Huang SH, Mokasdar A, Zhou H, Hou L (2014) The impact of additive manufacturing in the aircraft spare parts supply chain: supply chain operation reference (scor) model based analysis. Prod Plan Cont 25(13-14):1169-1181

Mai J, Zhang L, Tao F, Ren L (2016) Customized production based on distributed 3D printing services in cloud manufacturing. Int J Adv Manuf Technol 84(1-4):71-83

Makakli ES (2017) Potential of smart materials for sustainable architecture. Int J Soc Sci 55:267-275

Mattson S, Salunke O, Fast-Berglund A, Li D, Skoogh A (2018) Design concept towards a humancentered learning factory. Procedia Manuf 25:526-534

Mohamed AS (2017) Smart materials innovative technologies in architecture: towards innovative design paradigm. Energy Procedia 115:139-154

Mosterman PJ, Zander J (2016) Industry 4.0 as a cyber-physical system study. Soft Syst Model 15(1):17-29 
OECD (2013) Nanotechnology for green innovation. (O. Publishing, Ed.) OECD Science, Technology and Industry Policy Papers, 5

Oettmeier K, Hofmann E (2016) Impact of additive manufacturing technology adoption on supply chain management processes and components. J Manuf Technol Manage 27(7):944-968

Parry GC, Brax SA, Maull RS, Ng IC (2016) Operationalising IoT for reverse supply: the development of use-visibility measures. Supply Chain Manage Int J 21(2):228-244

Phaal R, Farrukh CJ, Probert DR (2006) Technology management tools: concept, development and application. Technovation 26:336-344

Porter AL (2010) Technology foresight: types and methods. Int J Foresight Innov Policy 6(1-3):3645

Prasad S, Zakaria R, Altay N (2018) Big data in humanitarian supply chain networks: a resource dependence perspective. Ann Oper Res 270(1-2):383-413

Rohrbeck R, Heuer J, Arnold H (2006) The technology radar-an instrument of technology intelligence and innovation strategy. In: The 3rd IEEE international conference on management of innovation and technology, Singapore, pp 978-983

Roper AT, Cunningham SW, Porter AL, Mason TW, Rossini FA, Banks J (2011) Forecasting and management of technology. Wiley, New York, NY

Rüßmann M, Lorenz M, Gerbert P, Waldner M, Justus J, Engel P, Harnisch M (2015) Industry 4.0: the future of productivity and growth in manufacturing industries. Boston Consulting Group

Sardesai S, Stute M, Fornasiero R, Kalaitzi D, Barros AC, Multu C, Muerza V (2020) Future scenario settings for supply chains. In: Fornasiero et al (ed) Next generation supply chains: a roadmap for research and innovation, Springer

Stute M, Sardesai S, Parlings M, Senna P, Fornasiero R, Balech S (2020) Technology scouting to accelerate innovation in supply chain. In: Fornasiero et al (ed) Next generation supply chains: a roadmap for research and innovation, Springer

Tsao Y-C, Linh V-T, Lu J-C (2017) Closed-loop supply chain network designs considering RFID adoption. (Elsevier, Ed) Comput Ind Eng 716-726

Warnke P, Heimeriks G (2008) Technology foresight as innovation policy instrument learning from science and technology studies. In: Cagnin C, Keenan M, Johnston R, Scapolo F, Barre R (eds) Future-oriented technology analysis. Springer, Heidelberg

West DM (2016) Achieving sustainability in a 5G world. The brooking institution, governance studies. Certer for technology innovation at brookings, Washington, DC

Open Access This chapter is licensed under the terms of the Creative Commons Attribution 4.0 International License (http://creativecommons.org/licenses/by/4.0/), which permits use, sharing, adaptation, distribution and reproduction in any medium or format, as long as you give appropriate credit to the original author(s) and the source, provide a link to the Creative Commons license and indicate if changes were made.

The images or other third party material in this chapter are included in the chapter's Creative Commons license, unless indicated otherwise in a credit line to the material. If material is not included in the chapter's Creative Commons license and your intended use is not permitted by statutory regulation or exceeds the permitted use, you will need to obtain permission directly from the copyright holder.

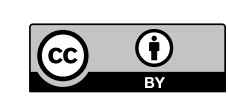

